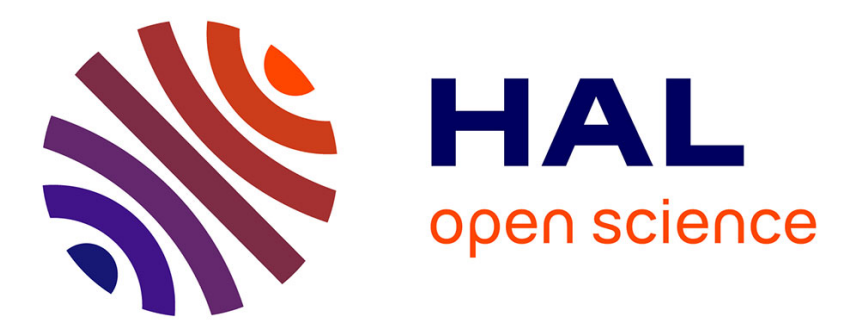

\title{
Veto power and coalition formation in the commons: an experiment
}

\author{
Marc Willinger, Oussama Rhouma, Klarizze Anne Puzon
}

\section{To cite this version:}

Marc Willinger, Oussama Rhouma, Klarizze Anne Puzon. Veto power and coalition formation in the commons: an experiment. 2021. hal-03227335

\section{HAL Id: hal-03227335 \\ https://hal.inrae.fr/hal-03227335}

Preprint submitted on 17 May 2021

HAL is a multi-disciplinary open access archive for the deposit and dissemination of scientific research documents, whether they are published or not. The documents may come from teaching and research institutions in France or abroad, or from public or private research centers.
L'archive ouverte pluridisciplinaire HAL, est destinée au dépôt et à la diffusion de documents scientifiques de niveau recherche, publiés ou non, émanant des établissements d'enseignement et de recherche français ou étrangers, des laboratoires publics ou privés.

\section{(ㅇ)(1) $\$$}

Distributed under a Creative Commons Attribution - NonCommercial - NoDerivatives| 4.0 


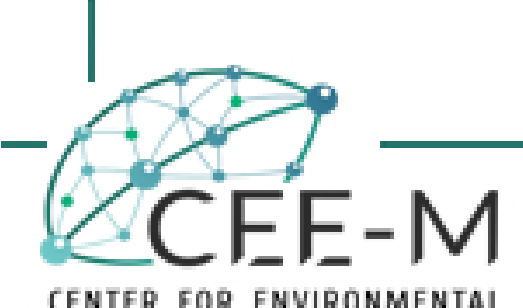
ECONOMICS - MONTPELLIER

Veto power and coalition formation in the commons: an experiment

\author{
Marc Willinger \\ Oussama Rhouma \\ \& \\ Klarizze Anne Puzon
}

CEE-M Working Paper 2021-09 


\title{
Veto power and coalition formation in the commons: an experiment.
}

\author{
Marc Willinger $^{1 *}$, Oussama Rhouma ${ }^{2}$, Klarizze Anne Puzon ${ }^{3}$
}

\begin{abstract}
We propose a five-player common-pool resource (CPR) game with endogenous coalition formation. We show that the level of extraction from the CPR depends on the size of each coalition that is formed and on the final coalition structure. These predictions are tested in a laboratory experiment. We consider two treatments: dictator vs. veto. In the dictator treatment, at each stage of the coalition formation game, a randomly chosen player imposes the coalition size and selected members cannot refuse to become a member. In the veto treatment, players have the right to refuse joining the current coalition if they want to and make counter-proposals. We observe that the formation of the grand coalition is more frequent in the dictator treatment. However, with the repetition of the coalition formation game, the grand coalition becomes more frequent under both treatment, and past experience of a grand coalition increases the likelihood that the current coalition structure is the grand coalition. Finally, the possibility to form coalitions is beneficial at reducing CPR extractions, compared to the singleton structure, in both treatments.
\end{abstract}

JEL: C92, C71, Q01, H41

Keywords: coalition formation, laboratory experiment, veto power, common pool resource

Acknowledgments: We thank Ismaël Rafai for insightful discussions and advice about the statistical analyses. Thanks to Yukihiko Funaki for useful comments on a previous version. All potential errors are ours.

${ }^{1}$ CEE-M, Univ Montpellier, CNRS, INRAE, SupAgro, Montpellier, France marc.willinger@umontpellier.fr

${ }^{2}$ Université de Jendouba, Ecole Supérieure des Ingénieurs de Medjez el Bab (ESIM), UR-Gestion Durable des Ressources en Eau et en Sol, P5, 9070, Tunisia

${ }^{3}$ UNU-WIDER, United Nations, Helsinki, Finland \& Center for Environmental and Resource Economics, Umea, Sweden

${ }^{*}$ Corresponding author 


\section{Introduction}

Over the last fifty years the tragedy of the commons (Hardin, 1968) changed scale: climate change, biodiversity losses and global exhaustion of minerals witness these change of scale. Designing appropriate policies for addressing such global issues requires first that countries agree to cooperate. For instance, countries need to agree on the level of carbon emissions, the level of fish stock that can be captured, or the list of species to protect. While global agreements that are ratified by all countries are rare, there is an increasing number of "partial agreements" among a few countries (Nordhaus, 2015). For instance, groups of countries take initiatives by making agreements to curb global warming (e.g. the UN framework convention on climate change) or to restore biodiversity at the global scale (e.g. UN biodiversity convention ${ }^{1}$ ).

An important question is therefore whether such agreements among a limited number of countries, are capable of reaching a sustainable path of exploitation of common pool resources (CPR thereafter) at the global scale. The case of the Kyoto Protocol for the climate resource/public good offers a disappointing illustration of a failure. Are there ways to design international agreements that could lead to a sustainable path of CPRs exploitation? According to cooperative game theory, such outcome is possible only under universal adherence, i.e. efficient outcomes require the grand coalition to be formed. When several smaller coalitions coexist, free riding and inefficiencies usually arise as demonstrated by the large theoretical literature on coalition formation (see, Hart and Kurz (1983), d'Aspremont et al. (1983), Barrett (1994), Carraro and Siniscalco (1993), Bloch (1995, 1996), Hoel et al. (1997), Ray and Vohra (1999, 2001), Funaki and Yamoto (1999, 2014), Nordhaus (2015), Finus and McGinty (2019)). Interestingly, in the case of CPRs, Funaki and Yamato (1999) showed that a key reason for the coexistence of several small coalitions, is the nature of the expectations of the members of a coalition (the insiders) regarding the coalition formation by outsiders. If insiders hold “pessimistic expectations" about outsiders' coalition decisions (i.e. outsiders make the worst possible choice for insiders) the grand coalition is formed. On the other hand, if insiders have

\footnotetext{
${ }^{1}$ The US have not signed the convention.
} 
"optimistic expectations" (outsiders make coalition decisions that are favorable to the insiders), the core is empty and the grand coalition cannot be reached.

Experimental evidence of inefficient coalition formation was provided by Thoron et al. (2009) in the context of a public good game. They showed, both theoretically and experimentally, that asymmetric coalition structures frequently emerge, in which a small coalition free rides on a larger one. Experiments on the provision of a public good, with endogenous coalition formation, have also been carried out by Ehrhart and Keser (1999), Ahn et al. (2008, 2009) and Brekke et al. (2011), leading to a similar finding of inefficiency. Little is known however, in the case of CPRs exploitation. In contrast to pure public goods, CPRs are characterized by rivalry, which may accentuate the tension among players, and therefore provide sharper incentives to cooperate. We are aware of only one (unpublished) paper by Chavez et al. (2021) that studies, theoretically and experimentally, the relation between the size of coalitions and monitoring costs in CPRs. The fundamental issue of the effectiveness of the formation of coalitions to prevent the overexploitation of CPRs, has however not yet been addressed by the experimental literature ${ }^{2}$.

In this paper, we study a common pool resource game (CPR) with endogenous coalition formation. We rely on a theoretical model of endogenous coalition formation in the spirit of Ray and Vohra (1999, 2001), to derive equilibrium predictions for different population sizes. In each stage of the game, one of the players is selected to be the proposer. The proposer's task is to form a coalition by choosing a coalition size. He can choose any size, from the singleton to the number of players that are not yet a member of an existing coalition. Besides the proposer, members of the potential coalition are randomly selected among players who are not yet a member of an existing coalition. We consider two treatments: the dictator treatment and the veto treatment. In the dictator treatment, the proposer makes a binding decision: players who are selected to become a member of the coalition cannot refuse. In contrast, in the veto treatment, selected members of the standing coalition are simultaneously asked to accept or reject the proposal. If all of them accept, the coalition is definitely formed and a new proposer is designated to form the next coalition. If at least one of the prospective members rejects the offer, the proposal is cancelled.

\footnotetext{
${ }^{2}$ Coalition formation games have however been extensively studied for CPR issues, in particular for the case of fisheries (e.g. Pintassilgo, P. (2003), Pintassilgo et al. (2010), Chavez et al. (2018), Chavez et al. (2021)) and in a more general framework by Funaki and Yamoto (1999, 2014).
} 
One of the prospective members who rejected is then designated to make a new proposal. The process of coalition formation goes on until all players are assigned to a coalition. The resulting structure can be any partition of the set of players, ranging from the collection of singletons to the grand coalition. Once the coalition structure is determined, all players are informed about the size of their own coalition as well as the sizes of all other coalitions. Then, each coalition chooses a common extraction level from the CPR. In the dictator treatment the proposer imposes the same level of extraction to each member of the group. In the veto treatment, in each coalition, each member announces a level of extraction. The smallest extraction level is selected as the common level in each coalition.

We test our predictions based on a laboratory experiment. We consider player sets with 5 participants. The unique non-cooperative equilibrium, assuming a tie-breaking rule that favors the largest coalition, is the grand coalition of the five players. Our results show that the possibility to form coalitions lowers resource extraction for all coalition structures compared to the singleton structure. Subjects in the dictator treatment are more likely to form the grand coalition, than subjects in the veto treatment. Intuitively, this result might be driven by more coordination difficulties in the veto treatment. Formation of a grand coalition fails even if just one out of the five players hesitate and deviate from doing so. This is not the case for the dictator treatment where coalition formation is imposed by only one decision-maker. As a result, subjects under veto power tend to have larger aggregate group extraction of the resource. Nonetheless, this finding is mitigated by a learning effect where those in the veto treatment who experienced forming grand coalitions in the past increase their probability of staying in a grand coalition. At the individual level, we observe that individual extractions are lower in larger coalitions, whatever the coalition structure and the treatment, as predicted.

Our behavioral findings have pertinent implications on the global commons. There is unsustainability of global agreements due to coordination frictions, especially if one powerful country can veto policy. Integral as well is provision of sufficiently large economic incentives to cooperate in resource conservation.

In section 2 we introduce our theoretical framework. Section 3 presents the coalition formation game. In section 4 we describe the experimental design. Section 5 is devoted to our experimental results and section 6 concludes. 


\section{The model}

\subsection{Common-pool resource extraction game}

Let $u_{i}\left(w_{i}, x_{i}, X\right)$ be the utility of player $i=1, \ldots, n$, where $w_{i}$ is his endowment and $\mathrm{x}_{\mathrm{i}}$ his appropriation effort. We note $X=\sum_{j=1}^{n} x_{j}$ the group's aggregate extraction effort. We assume that total extraction is a quadratic function of the appropriation effort, $F(X)=\alpha X-\beta X^{2}$, as in Walker et al. (1994). As long as players are isolated, i.e. they do not belong to a coalition, their share of the total extraction depends only on their relative effort. Player $i$ 's share of the resource is therefore equal to $\frac{x_{i}}{X}$. With these hypotheses, his utility is given by expression (1):

$$
u_{i}\left(w_{i}, x_{i}, X\right)=\theta\left(w_{i}-x_{i}\right)+\frac{x_{i}}{X}\left(\alpha X-\beta X^{2}\right),
$$

where $\theta$ is the marginal return of the private activity.

We consider a symmetric game, i.e. all players have the same endowment and the same utility function. Players who belong to a coalition divide equally the coalition's payoff. This means that they make the same effort and get the same reward. A coalition of size $s$ invests $\mathrm{X}_{\mathrm{s}}$ and receives a share $\frac{\mathrm{X}_{\mathrm{s}}}{\mathrm{X}}$ of the output. The utility of player $i$ who belongs to a coalition of size $s$ is therefore given by (2):

$$
u_{i}(w, x, X)=\theta(w-x)+\frac{1}{s} \frac{X_{s}}{X}\left(\alpha X-\beta X^{2}\right)
$$

with $\mathrm{X}_{\mathrm{s}}=\mathrm{s}$. $\mathrm{x}$ (i.e. each member of the coalition of size s makes the same extraction effort, $\mathrm{x}$ ).

In the standard game, players do not have the possibility to form coalitions, i.e. $s=1$. The symmetric Nash equilibrium level of individual extraction is therefore $x^{*}=\frac{\alpha-\theta}{(n+1) \beta}$. In contrast the socially optimum individual extraction is equal to the lower level, $\hat{x}=\frac{\alpha-\theta}{2 n \beta}<x^{*}$. In the next subsection we show that the possibility to form coalitions leads to lower levels of equilibrium extraction.

\subsection{Optimal and equilibrium extraction}


In order to determine the equilibrium structure of the coalition formation game, let us define $u_{s_{i}}$ player $i$ 's utility when the size of the coalition he belongs to is $\mathrm{s}_{\mathrm{i}}$. Player $i$ 's utility not only depends on the size of his own coalition, but also on the size distribution of all coalitions. This is written as expression (3):

$$
u_{s_{i}}\left(w, x ; s_{1}, \ldots, s_{m}\right)=s_{i}\left[\theta\left(w-x_{i}\right)+\frac{x_{i}}{X}\left(\alpha X-\beta X^{2}\right)\right],
$$

in which $m$ is the total number of coalitions and $\mathrm{s}_{\mathrm{k}},(k=1, \ldots, m)$, is the size of coalition $\mathrm{k}$.

Player $i$ 's utility can be rewritten as expression (4):

$$
u_{s_{i}}\left(w, x ; s_{1}, \ldots, s_{m}\right)=\theta s_{i}\left(w-x_{i}\right)+s_{i} x_{i}\left(\alpha-\beta \sum_{k=1}^{m} s_{k} x_{k}\right)
$$

The first order condition of the optimal (uniform) group contribution is:

$$
\frac{\partial u_{s_{i}}}{\partial x_{i}}=s_{i}(\alpha-\theta)-\beta s_{i}\left(X+s_{i} x_{i}\right)=0
$$

which leads to: $\frac{(\alpha-\theta)}{\beta}-X=s_{i} x_{i}$

Summing the m equations we obtain:

$$
m\left[\frac{(\alpha-\theta)}{\beta}-X\right]=\sum_{i=1}^{m} s_{i} x_{i} \Leftrightarrow X=m \frac{(\alpha-\theta)}{\beta(m+1)}
$$

and finally:

$$
x_{i}=\frac{(\alpha-\theta)}{\beta(m+1) s_{i}}
$$

From expression (7) we can see that player $i$ 's extraction effort is decreasing in the number of coalitions $(m)$ and in the size of the coalition he belongs to $\left(s_{i}\right)$.

Substituting $X$ and $x_{i}$ in player $i$ 's utility function leads to expression (8):

$$
u_{s_{i}}\left(w, x ; s_{1}, \ldots, s_{m}\right)=\theta s_{i}\left(w-\frac{(\alpha-\theta)}{\beta(m+1) s_{i}}\right)+s_{i} \frac{(\alpha-\theta)}{\beta(m+1) s_{i}}\left(\alpha-\beta m \frac{(\alpha-\theta)}{\beta(m+1) s_{i}}\right)
$$

Which simplifies to:

$$
u_{s_{i}}\left(w, x ; s_{1}, \ldots, s_{m}\right)=\theta s_{i} w+\frac{(\alpha-\theta)^{2}}{\beta(m+1)^{2}}
$$


The utility of player $k$ who belongs to a coalition of size $\mathrm{s}_{\mathrm{i}}$ is obtained by dividing by $\mathrm{s}_{\mathrm{i}}$ to obtain:

$$
u_{k / s_{i}}\left(w, x ; s_{1}, \ldots, s_{m}\right)=\theta w+\frac{(\alpha-\theta)^{2}}{\beta(m+1)^{2} s_{i}}
$$

Two extreme cases are worth considering: the structure of singletons $\left(\mathrm{m}=\mathrm{n}\right.$ with $\left.s_{i}=1, \forall i\right)$ and the grand coalition $(\mathrm{m}=1$ with $s=n)$. In the structure of singletons $s_{i}=1, \forall i$. Player $k$ 's utility is: $u_{k}(w, x, 1,1, \ldots, 1)=\theta w+\frac{(\alpha-\theta)^{2}}{\beta(n+1)^{2}}$, where $\frac{(\alpha-\theta)}{\beta(m+1)}$ is the Nash extraction level. Therefore for the coalition structure $(1,1, \ldots, 1)$, the total extraction is $X^{*}=n \frac{(\alpha-\theta)}{\beta(n+1)}=n x^{*}$. On the other hand, with the grand coalition player $k$ 's utility becomes: $u_{k}(w, x, n)=\theta w+\frac{(\alpha-\theta)^{2}}{\beta(2)^{2} n}$, where $\frac{(\alpha-\theta)}{2 \beta n}=\hat{x}$ is the Pareto optimum extraction level. Therefore, if the grand coalition is formed, the total extraction is $\widehat{X}=n \hat{x}$.

\section{Coalition formation game with veto power}

We assume that the coalition formation game is played according to the following rules. In each step, a player who does not yet belong to a coalition, is randomly selected to be the proposer. The proposer chooses a coalition size. If only one player is left, i.e. the proposer himself, he has no choice but to choose a singleton. If two players are left, he can choose a coalition of two or a singleton. If p players are left, he can choose any coalition size between 1 and $\mathrm{p}$. If he decides to form a singleton, the coalition is immediately formed. If he chooses a coalition of size $\mathrm{m}$, with 1 $<\mathrm{m} \leq \mathrm{p}$, the candidate members of the coalition (the responders) are randomly selected among the players that are not yet assigned to a coalition. We consider two rules for the responders: the dictator procedure (D) and the veto procedure (V). Under the D procedure, responders have no say: they are assigned in an authoritarian manner. Under the $\mathrm{V}$ procedure, the responders can decide to accept or to reject the proposer's offer, i.e. to accept or to reject to be a member of the proposed coalition. If at least one of the responders rejects the offer, the coalition is not formed and one of the responders who rejected the offer is randomly selected to become the next proposer. This process goes on until all players are assigned to a coalition. Once a coalition is formed it is definite. Multiplicity of equilibria can arise when a player is indifferent between two coalitions, either as a proposer or as a responder. In order to avoid such outcome, we assume a tie-breaking rule: if a player is indifferent between two coalition sizes, he selects the largest size. Of course, in the experiment, we cannot guarantee that subjects will adopt such a rule. However, from a theoretical point of view, assuming a tie-breaking rule simplifies the demonstration by 
preventing the multiplicity of equilibria. We nevertheless address the issue of multiplicity of equilibria in the discussion.

To simplify the presentation of the equilibrium outcome, we always consider that player $i$ is the proposer and player $k$ one of the responders. We derive the proposer's (player $i$ ) and the responders' (player $k$ ) best responses in each possible subgame. A subgame corresponds to a number of remaining players. In our experiment we consider populations of 5 players. We shall therefore derive the equilibrium solution for $\mathrm{n}=5$. We denote player $k$ 's utility if he accepts player $i$ 's proposition of a coalition of size $\mathrm{s}_{\mathrm{i}}$ as follows:

$$
u_{k / s_{i}}\left(w, x ; s_{1}, \ldots, s_{m}\right)=\theta w+\frac{(\alpha-\theta)^{2}}{s_{i} \beta\left(m_{1}+m_{2}+1\right)^{2}}
$$

where $\mathrm{m}_{1}$ is the number of coalitions already formed before player $i$ makes a new proposal and $\mathrm{m}_{2}$ is the number of additional coalitions resulting from player $i$ 's decision. We proceed recursively, by considering the number of remaining agents that are not yet a member of a coalition. If only one player remains unassigned, he has no choice but form a singleton. In all other cases, there are several options that we discuss below. We will use the notation $k P$ to designate a $\mathrm{k}$ player coalition.

\subsection{Two players are left $(p=2)$}

If only two players remain, there are two possibilities: player $i$ can propose a coalition of two $\left(\mathrm{m}_{2}\right.$ $=1$ and $\left.\mathrm{s}_{\mathrm{i}}=2\right)$ or a singleton $\left(\mathrm{m}_{2}=2\right.$ and $\left.\mathrm{s}_{\mathrm{i}}=1\right)$. If he chooses to stand alone, the remaining player has no other option than to form a singleton. Both player $k$ 's utility and player $i$ 's utility are therefore defined as follows:

(i) 2P coalition:

$$
u_{k / s_{i}}\left(w, x ; s_{1}, \ldots, s_{m}\right)=\theta w+\frac{(\alpha-\theta)^{2}}{2 \beta\left(m_{1}+1+1\right)^{2}}
$$

(ii) Singleton :

$$
u_{k / s_{1}}\left(w, x ; s_{1}, \ldots, s_{m}\right)=\theta w+\frac{(\alpha-\theta)^{2}}{\beta\left(m_{1}+2+1\right)^{2}},
$$

If player $i$ proposes a $2 \mathrm{P}$ coalition, the remaining player (i.e. player $k$ ) accepts if $2\left(m_{1}+2\right)^{2}<$ $\left(m_{1}+3\right)^{2}$. If $\mathrm{n}=2$ the inequality is satisfied and the $2 \mathrm{P}$ coalition is formed. For $\mathrm{n}>2$, since $\mathrm{m}_{1}$ is a strictly positive integer, the opposite inequality holds and player $i$ chooses the singleton. 


\subsection{Three players are left $(p=3)$}

Player $i$ can choose to stay alone, form a $2 \mathrm{P}$ coalition or a $3 \mathrm{P}$ coalition. Let us determine the utility corresponding to each possibility.

(i) Singleton :

If player $i$ decides to form a singleton, from subgame $p=2$ we know that the two remaining players will also form singletons. Therefore, player $i$ 's utility will be:

$$
u_{k / 1}\left(w, x ; s_{1}, \ldots, s_{m}\right)=\theta w+\frac{(\alpha-\theta)^{2}}{\beta\left(m_{1}+3+1\right)^{2}}
$$

(ii) $2 \mathrm{P}$ coalition:

If player $i$ decides to form a 2P coalition, the remaining player will stand alone. Therefore, player i’s utility will be:

(iii) $3 \mathrm{P}$ coalition :

$$
u_{k / 2}\left(w, x ; s_{1}, \ldots, s_{m}\right)=\theta w+\frac{(\alpha-\theta)^{2}}{2 \beta\left(m_{1}+2+1\right)^{2}}
$$

The 3P leads to:

$$
u_{k / 3}\left(w, x ; s_{1}, \ldots, s_{m}\right)=\theta w+\frac{(\alpha-\theta)^{2}}{3 \beta\left(m_{1}+1+1\right)^{2}}
$$

If $\mathrm{n}=3$ (i.e., $\mathrm{m}_{1}=0$ ) it is easy to see that each player's utility is maximized for the 3P coalition. However if $\mathrm{n} \geq 4\left(\mathrm{~m}_{1}>0\right)$, player $i$ is better off by choosing the stand alone option. For instance if $\mathrm{n}=4, \beta\left(m_{1}+4\right)^{2}<2 \beta\left(m_{1}+3\right)^{2}$ and $\beta\left(m_{1}+4\right)^{2}<3 \beta\left(m_{1}+2\right)^{2}$. More generally, if $\mathrm{n}>3$ player $i$ chooses the singleton and from subgame $p=2$ we know that the two remaining players will do the same.

\subsection{Four players are left $(p=4)$}

Player $i$ has to choose between staying alone, a 2P coalition, a 3P coalition or a 4P coalition. Let us determine his utility level in each case.

(i) Singleton : 
If player $i$ decides to form a singleton, we know from the preceding steps that the remaining three players will do the same. Therefore player $i$ 's utility is given by:

$$
u_{k / 1}\left(w, x ; s_{1}, \ldots, s_{m}\right)=\theta w+\frac{(\alpha-\theta)^{2}}{\beta\left(m_{1}+4+1\right)^{2}}
$$

(ii) $2 \mathrm{P}$ coalition:

If player $i$ proposes a $2 \mathrm{P}$ coalition, the two remaining players will form singletons according to subgame $p=2$. Player $i$ 's utility is therefore equal to:

$$
u_{k / 2}\left(w, x ; s_{1}, \ldots, s_{m}\right)=\theta w+\frac{(\alpha-\theta)^{2}}{2 \beta\left(m_{1}+3+1\right)^{2}}
$$

The expressions for the $3 \mathrm{P}$ and the $4 \mathrm{P}$ are given below:

(iii) $3 \mathrm{P}$ coalition :

$$
u_{k / 3}\left(w, x ; s_{1}, \ldots, s_{m}\right)=\theta w+\frac{(\alpha-\theta)^{2}}{3 \beta\left(m_{1}+2+1\right)^{2}}
$$

(iv) $4 \mathrm{P}$ coalition :

$$
u_{k / 4}\left(w, x ; s_{1}, \ldots, s_{m}\right)=\theta w+\frac{(\alpha-\theta)^{2}}{4 \beta\left(m_{1}+1+1\right)^{2}}
$$

The choice of player $i$ is determined by which of the following expressions is the smallest: $\left(m_{1}+5\right)^{2}, 2\left(m_{1}+4\right)^{2}, 3\left(m_{1}+3\right)^{2}$ or $4\left(m_{1}+2\right)^{2}$.

If $\mathrm{n}=4,\left(\mathrm{~m}_{1}=0\right)$ player $i$ proposes the largest coalition $4 \mathrm{P}$ and all remaining players accept it. If $n \geq 5$, there are three possible Nash equilibria depending on whether $m_{1}=1$ or $m_{1}>1$. If $m_{1}=$ 1 there are two possible equilibria as player $i$ is indifferent between staying alone and proposing a 4P: indeed $\beta\left(m_{1}+5\right)^{2}=4 \beta\left(m_{1}+2\right)^{2}$. However, according to our tie-breaking rule the unique solution is $4 \mathrm{P}$. If he chooses a $2 \mathrm{P}$ coalition the 2 remaining players will form singletons according to the subgame $p=2$. If he proposes a $3 \mathrm{P}$ the responders will be indifferent between accepting and rejecting the $4 \mathrm{P}$ proposal ${ }^{3}$. The two corresponding equilibria are therefore $\left(\mathrm{m}_{1}, 4\right)$ and $\left(\mathrm{m}_{1}\right.$, $1,1,1,1)$.

\footnotetext{
${ }^{3}$ A player who rejects such proposal could have the opportunity to form a singleton and achieve the same level of payoff than if he accepted the proposal.
} 
If $\mathrm{m}_{1}>1$ player $i$ chooses a singleton and according to the subgame $p=3$ the remaining players will do the same.

\subsection{Five players left $(p=5)$}

There are two possible cases: $\mathrm{m}_{1}=0$ and $\mathrm{m}_{1}>0$. Since the experiment considers only populations of 5 players, we study only the case $n=5$, i.e. $\mathrm{m}_{1}=0$. The first selected proposer can choose any coalition size, between a singleton and a $\mathrm{kP}$ coalition, with $k=2, \ldots, 5$.

(i) Singleton :

From the previous step we know that if the first proposer constitutes a singleton, the second proposer is indifferent between a $4 \mathrm{P}$ coalition and a coalition structure that consists of four singletons. Indeed:

$$
\begin{aligned}
& u_{k / 1}\left(w, x ; s_{1}, \ldots, s_{m}\right)=\theta w+\frac{(\alpha-\theta)^{2}}{\beta\left(m_{1}+5+1\right)^{2}}=\theta w+\frac{(\alpha-\theta)^{2}}{36 \beta} \\
& u_{k / 4}\left(w, x ; s_{1}, \ldots, s_{m}\right)=\theta w+\frac{(\alpha-\theta)^{2}}{4 \beta\left(m_{1}+2+1\right)^{2}}=\theta w+\frac{(\alpha-\theta)^{2}}{36 \beta}
\end{aligned}
$$

(ii) $2 \mathrm{P}$ coalition:

$$
u_{k / 2}\left(w, x ; s_{1}, \ldots, s_{m}\right)=\theta w+\frac{(\alpha-\theta)^{2}}{2 \beta\left(m_{1}+4+1\right)^{2}}=\theta w+\frac{(\alpha-\theta)^{2}}{50 \beta}
$$

If player $k$ accepts a $2 \mathrm{P}$ coalition proposal for the first proposer, the three remaining players will form singletons according to the subgame $p=3$. His utility will therefore be:

$$
u_{k / 2}\left(w, x ; s_{1}, \ldots, s_{m}\right)=\theta w+\frac{(\alpha-\theta)^{2}}{2 \beta\left(m_{1}+4+1\right)^{2}}=\theta w+\frac{(\alpha-\theta)^{2}}{50 \beta}
$$

If he rejects the $2 \mathrm{P}$ coalition, he becomes the next proposer and can obtain a larger utility, by choosing for instance a $3 \mathrm{P}$ coalition.

(iii) 3P coalition:

$$
u_{k / 3}\left(w, x ; s_{1}, \ldots, s_{m}\right)=\theta w+\frac{(\alpha-\theta)^{2}}{3 \beta\left(m_{1}+3+1\right)^{2}}=\theta w+\frac{(\alpha-\theta)^{2}}{48 \beta}
$$

If the $3 \mathrm{P}$ coalition proposal is accepted by the wo selected players, the 2 remaining players will form singletons according to subgame $p=2$. Their utility is therefore: 


$$
u_{k / 1}\left(w, x ; s_{1}, \ldots, s_{m}\right)=\theta w+\frac{(\alpha-\theta)^{2}}{\beta\left(m_{1}+3+1\right)^{2}}=\theta w+\frac{(\alpha-\theta)^{2}}{16 \beta}
$$

If one of them rejects the $3 \mathrm{P}$ coalition he can choose to form a larger coalition, 4P or 5P.

(iv) $4 \mathrm{P}$ coalition :

If the $4 \mathrm{P}$ is accepted by the selected players, the remaining player can only choose to stand alone. The utility of the members of the $4 \mathrm{P}$ coalition is therefore:

$$
u_{k / 4}\left(w, x ; s_{1}, \ldots, s_{m}\right)=\theta w+\frac{(\alpha-\theta)^{2}}{4 \beta\left(m_{1}+2+1\right)^{2}}=\theta w+\frac{(\alpha-\theta)^{2}}{36 \beta}
$$

However the selected players to become members of the $4 \mathrm{P}$ can achieve a higher payoff by rejecting this proposal in order to form a $5 \mathrm{P}$ coalition.

(v) 5P coalition:

$$
u_{k / 5}\left(w, x ; s_{1}, \ldots, s_{m}\right)=\theta w+\frac{(\alpha-\theta)^{2}}{5 \beta\left(m_{1}+1+1\right)^{2}}=\theta w+\frac{(\alpha-\theta)^{2}}{20 \beta}
$$

Two equilibria are possible depending on player $i$ 's expectations on the issue of subgame $p=4$ : (i) if player $i$ expects that the remaining players will form a $4 \mathrm{P}$ coalition in subgame $p=4$ he chooses to stand alone, (ii) if on the other hand he expects the remaining players to form singletons in subgame $p=4$ he proposes a 5P coalition. If we apply the tie-breaking rule the only equilibrium if 5P. If there is no tie-breaking rule, player $i$ 's proposal of the $5 \mathrm{P}$ coalition could be rejected by a player $k$ who expects that if he chooses to stand alone the other players will form a $4 \mathrm{P}$ coalition.

Table 1 summarizes the possible equilibria according to the number of players. 


\begin{tabular}{|c|c|c|c|}
\hline $\begin{array}{c}\text { Number of } \\
\text { players }\end{array}$ & \multicolumn{3}{|c|}{ Tie-breaking rule } \\
\hline & Largest coalition & Singleton & Indifference (coin flip) \\
\hline 2 & $(2)$ & $(2)$ & $(3)$ \\
\hline 3 & $(3)$ & $(3)$ & $(4)$ \\
\hline 4 & $(4)$ & $(4)$ & $(1,4)$ or $(5)$ \\
\hline 5 & $(5)$ & $(1,4)$ & $(3)$ \\
\hline
\end{tabular}

Table 1. Equilibrium coalition structures according to the tie-breaking rule

\section{Experimental setting}

\subsection{Coalition formation rules}

In each session, participants were randomly assigned to a set of five players and were made aware that they would remain in the same set of players throughout the whole experiment. In the instructions we used the word group instead of coalition. In the sequel we shall adopt the same terminology for presenting the results. The set of final coalitions formed in any given round will be referred to as the coalition structure as in previous sections.

Players' payoffs were determined by their investments in the collective account. In each group, all members had to invest the same amount in the collective account. We consider two allocation rules of the 10 tokens endowment between the private and the common accounts. In the dictator treatment this amount was decided uniquely by the founding member of the group. In the veto treatment each member of a group was asked to announce a level of investment in the collective account. The lowest amount announced was chosen to be the common level of investment of all the coalition members. Subjects were aware of this rule and were reminded that the collective account would benefit to all players of their set, no matter to which group they belonged to. Table 2 summarizes the payoff of each player according to the group to which he belongs to $(\mathrm{G} 1, \mathrm{G} 2, \ldots$, G5) and the final coalition structure (column 1). Coalition structures are indexed from the largest to the smallest. The last column of table 2 indicates the aggregate payoff of the five players of a set. Note that coalition structures with fewer groups achieve larger payoffs. 


\begin{tabular}{|c|c|c|c|c|c|c|}
\hline $\begin{array}{c}\text { Coalition } \\
\text { structure }\end{array}$ & G1 & G2 & G3 & G4 & G5 & Total \\
\hline $\begin{array}{c}(5) \\
\text { optimum }\end{array}$ & $3,[55]$ & & & & & $15,[275]$ \\
\hline$(4,1)$ & $2.5,[35]$ & $10,[110]$ & & & & $20,[250]$ \\
\hline$(3,2)$ & $10 / 3,[43.33]$ & $5,[60]$ & & & & $20,[250]$ \\
\hline$(3,1,1)$ & $2.5,[28.75]$ & $7.5,[66.25]$ & $7.5,[66.25]$ & & & $22.5,[218.75]$ \\
\hline$(2,2,1)$ & $3.75,[38.125]$ & $3.75[38.125]$ & $7.5,[66.25]$ & & & $22.5,[218.75]$ \\
\hline $\begin{array}{c}(2,1,1,1) \\
(1,1,1,1,1) \\
\text { Nash }\end{array}$ & $5,[28]$ & $6,[46]$ & $6,[46]$ & $6,[46]$ & & $24,[212]$ \\
\hline
\end{tabular}

Table 2. Group extractions [payoffs] and total extraction [payoff] for alternative coalition structures.

\subsection{Practical procedures}

In the experiment, we considered sets of five players. Each player of a set was endowed with 10 monetary units, so that total initial wealth was 50 monetary units per player set. We chose the values for the parameters $(\alpha=31, \beta=1$ and $\theta=1)$ in a way that in the absence of the possibility to form coalitions, the Nash extraction level is equal to 5 units per player and the social optimum to 3 units per player. More generally, when players can form coalitions the equilibrium level of extraction for player $i$ is:

$$
x_{i}=\frac{(\alpha-\theta)}{\beta(m+1) s_{i}}=\frac{30}{(m+1) s_{i}}
$$

and player $k$ 's utility as a member of a group of size $s_{i}$ is:

$$
u_{k / s_{i}}\left(w, x ; s_{1}, \ldots, s_{m}\right)=\theta w+\frac{(\alpha-\theta)^{2}}{\beta(m+1)^{2} s_{i}}=10+\frac{30^{2}}{(m+1)^{2} s_{i}}
$$

Prior to the coalition formation game, subjects played five rounds of the extraction game without the possibility to form coalitions. This part of the experiment was intended to let players discover the strategic interactions of the extraction game. We observed that extraction levels converged quickly to the Nash extraction level, i.e. 5 units, in all player sets, without significant differences 
(mean extraction $=5.08$, median $=5$ ). No significant difference was observed between veto sets and dictator sets. Given these findings, we conjecture that any difference observed in the second part of the experiment with respect to the first part, can be attributed to the possibility to form coalitions combined with the treatment variable (veto versus dictator).

The instructions are available in appendix 1 . Below we report the wording that was used in the dictator and the veto treatment. Note that the only difference is the possibility to accept or reject the membership proposal under the veto rule.

\section{Veto version of the instructions [dictator version in brackets]}

At the beginning of each period you will receive a pseudonym chosen from the set $\{A, B, C, D, E\}$. During a period, you will likely be required to form a group (in the event that you are selected to do so). To form a group, you just have to choose its size among the possible sizes. If you are the first to make a proposal, you can choose any group size between 1 and 5. If a group of size T1 is already formed then you can choose any size between 1 and 5-T1, etc... If during a period you are offered to join a group, [you cannot refuse], you will have to decide whether to accept or reject this offer. If you accept and all the members proposed for your group also accept, the group will be definitively formed. If you refuse, or if one of the proposed members for your group refuses, the group will not be formed. One of the people who refused will then be designated to make a new proposal.

Once all groups are formed, the computer will display your individual gain, the individual gain of each member of each group as well as the total gain achieved by all the members of all the groups (the sum of the gains of the 5 people in your subset).

\section{Results}

In what follows, we start the statistical analysis of group behavior (i.e. on the aggregate, given the initial set of 5 players) before we move to individual behavior. At the group level, we are interested in the groups that are formed in any given set of players and collective extraction. At the individual level, we are interested in individual extraction levels within groups.

\section{$5.1 \quad$ Group Behavior}

We first look at the frequency distribution of coalition structures reported in Table 3. Of particular interest is the frequency of the grand coalition in the dictator and veto treatments. We find that there is a significant difference $(\mathrm{Chi} 2, \mathrm{p}=0.000)$ in the distribution of group types across treatments. Almost 50\% of the sets form a grand coalition under dictator leadership, compared 
to only about $25 \%$ in the veto treatment, a significant difference (Fisher exact test, $\mathrm{p}=0.000$ ). We state this observation as Result 1.

Result 1. Subjects in the dictator treatment are more likely to form the grand coalition, than subjects in the veto treatment.

Table 3: Frequencies of coalition type by treatment

\begin{tabular}{|l|c|c|c|}
\hline \multicolumn{4}{|c|}{ Treatment } \\
Soalition & Dictator & Veto & Total \\
\hline$(1,1,1,1,1)$ & 0 & 16 & 16 \\
$(2,1,1,1)$ & 4 & 31 & 35 \\
$(2,2,1)$ & 10 & 11 & 21 \\
$(3,1,1)$ & 10 & 19 & 29 \\
$(3,2)$ & 25 & 5 & 30 \\
$(4,1)$ & 29 & 4 & 33 \\
$(5)$ & 72 & 34 & 106 \\
\hline Total & 150 & 120 & 270 \\
\hline
\end{tabular}

Interestingly, Table 3 also shows that no singletons structure is observed in the dictator treatment. In contrast, more than $10 \%$ of the coalition structures under veto are singletons structures. This may imply that, due to a coordination issue, individuals in the veto treatment sometimes use their power to avoid forming the grand coalition. Because everyone has veto power, even if only one person deviates, smaller sub-group sizes (e.g. singletons) become more likely. In contrast, players in the dictator treatment are only governed by one decision-maker. If the randomly chosen dictator wants to form a grand coalition or simply avoid smaller sub-groups, he is able to do so without needing the agreement of others.

Indeed, as shown by the probit regressions of Table 4, in the dictator treatment, player sets tend to prevent the formation of the singletons structure $(1,1,1,1,1,1)$ and seem more likely to form the grand coalition than player sets in the veto treatment. The dependent variable in Table 4 is the probability of the grand coalition. The main regressors are the dummy veto (equal to 1 for the veto treatment), the variable period which we take as a proxy for learning, and whether subjects of a set experienced the grand coalition in the past captured by the variable lag_grand (equal to 1 if in the previous period the grand coalition was formed). We add two interaction variables, veto $\times$ period which captures the time effect for the veto treatment and veto $\times$ lag_grand which 
accounts for the formation of the grand coalition in the previous period in the veto treatment. The variable veto affects negatively the likelihood that players form the grand coalition, but over time subjects learn and become more likely to form the grand coalition. As shown by the significance of the interaction variable vetoxperiod in regression (3), learning has a tempering effect for the negative impact of the veto dummy. Furthermore if the player set experienced the grand coalition in the previous period, the negative impact of the veto dummy is even more strongly attenuated. These findings are summarized in Result 2.

\begin{tabular}{|c|c|c|c|c|}
\hline & (1) & $(2)$ & (3) & (4) \\
\hline veto & $\begin{array}{c}-0.791^{*} \\
(-1.66)\end{array}$ & $\begin{array}{l}-0.688 \\
(-1.63)\end{array}$ & $\begin{array}{c}-1.863^{* * *} \\
(-2.71)\end{array}$ & $\begin{array}{c}-1.773^{* * *} \\
(-2.99)\end{array}$ \\
\hline period & $\begin{array}{c}0.067^{* * *} \\
(3.22)\end{array}$ & $\begin{array}{c}0.058^{* * *} \\
(2.73)\end{array}$ & $\begin{array}{c}0.031 \\
(1.21)\end{array}$ & $\begin{array}{l}0.026 \\
(1.04)\end{array}$ \\
\hline lag_grand & & $\begin{array}{c}0.388^{*} \\
(1.94)\end{array}$ & & $\begin{array}{l}0.018 \\
(0.08)\end{array}$ \\
\hline veto_period & & & $\begin{array}{c}0.121^{* *} \\
(2.48)\end{array}$ & $\begin{array}{c}0.081^{*} \\
(1.68)\end{array}$ \\
\hline veto_lag_grand & & & & $\begin{array}{c}1.146^{* * *} \\
(2.66)\end{array}$ \\
\hline _cons & $\begin{array}{c}-0.646^{*} \\
(-1.85)\end{array}$ & $\begin{array}{c}-0.740^{* *} \\
(-2.29) \\
\end{array}$ & $\begin{array}{l}-0.357 \\
(-0.92) \\
\end{array}$ & $\begin{array}{l}-0.304 \\
(-0.88) \\
\end{array}$ \\
\hline $\ln \operatorname{sig} 2 \mathrm{u}$ & $\begin{array}{l}-0.230 \\
(-0.46)\end{array}$ & $\begin{array}{l}-0.540 \\
(-0.96)\end{array}$ & $\begin{array}{l}-0.035 \\
(-0.07)\end{array}$ & $\begin{array}{l}-0.601 \\
(-1.02)\end{array}$ \\
\hline $\mathrm{N}$ & 270 & 269 & 270 & 269 \\
\hline $\mathrm{p}$ & 0.002 & 0.001 & 0.001 & 0.000 \\
\hline rho & 0.443 & 0.368 & 0.491 & 0.354 \\
\hline
\end{tabular}

Result 2. Although, player sets in the veto treatment are less likely to form the grand coalition than in the dictator treatment (veto power effect), the grand coalition becomes more likely over time in both treatments (learning effect). This tendency is reinforced if players experienced the grand coalition in the previous period.

We now look at the aggregate extraction levels by treatment. Let us recall that each player's endowment is equal to 10 tokens, so that the maximum possible extraction for a set of players is equal to 50 tokens. For the dictator treatment, the average group extraction is 18.19 , while for the veto treatment it is 20.83, a significant difference (t-test and Mann-Whitney U test, $\mathrm{p}=0.000$ ). Average group extractions are sandwiched between the Nash (25 units) and the optimum (15 units) levels. However, as illustrated by figure 1 the distributions look very different 
(Kolmogorov-Smirnov, $\mathrm{p}=0.000$ ), with a sharp spike on the optimum extraction level in the dictator treatment.

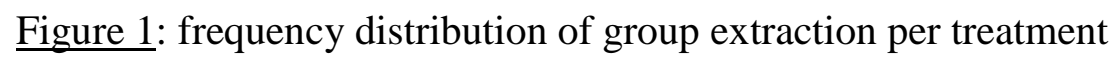

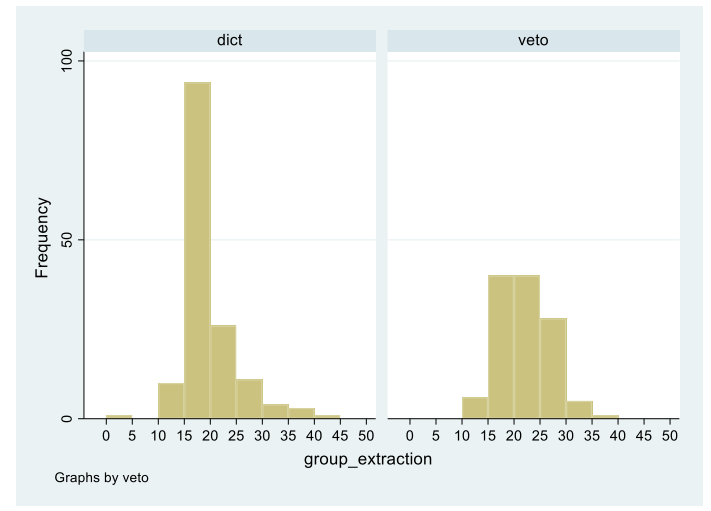

Table 5 reports the coefficients of OLS regressions ${ }^{4}$ with dependent variable total extraction by the 5 players of a set. The variable grand is equal to 1 if the grand coalition is formed. Other variables are the same as in previous tables. We control for the coalition structure, taking the singletons structure $(1,1,1,1,1)$ as the reference. The definitions of the other structures is the same as in Table 2. The significant negative sign of the variable grand shows that players in the grand coalition extract less than in other coalition structures. Furthermore, all coalition structures extract less than the singleton structure (see column 3). Allowing players to form coalitions is beneficial for the protection of the resource, and improves players' payoffs on average. The negative sign of the variable period also indicates a learning effect where total group extraction decreases over time. As shown by Figure 2, this learning effect allows groups in the dictator treatment to reach the efficient level of extraction. This learning effect is however counteracted for the veto treatment as shown by the positive significant sign of the variable veto $\times$ period. As in Result 2, we find that the learning effect is stronger than the veto power effect in terms of group extraction rates. We summarize these observations as Result 3.

Figure 2: average group extraction over time per treatment (fitted values, 95\% CI)

\footnotetext{
${ }^{4}$ Clustered errors at the session level.
} 


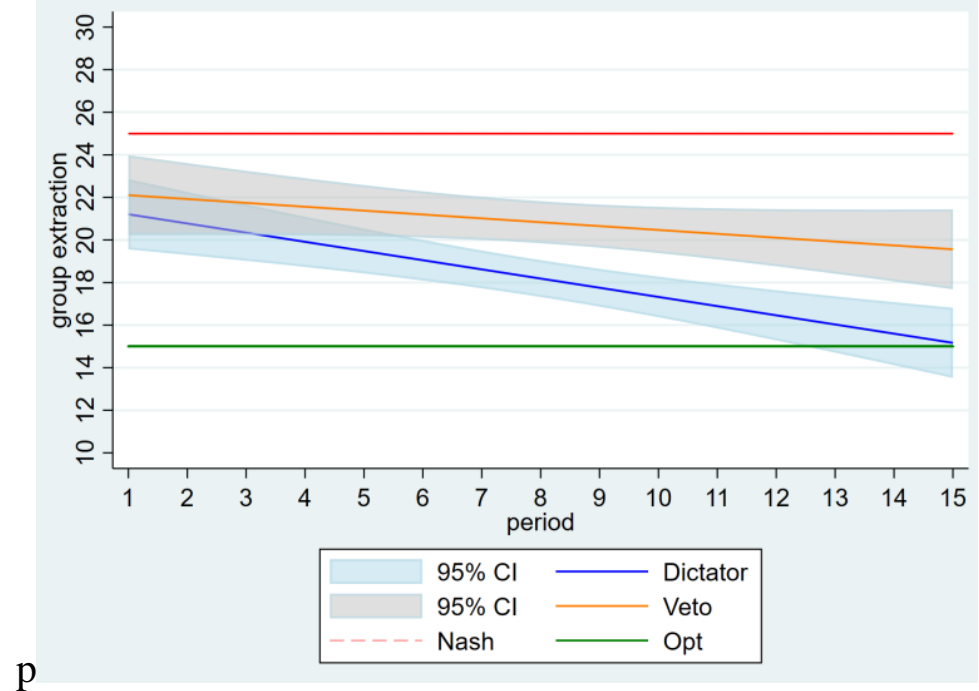

Result 3. The possibility to form coalitions lowers resource extraction for all coalition structures compared to the singleton structure. In the veto treatment, we observe a tendency to increase extractions, except if the grand coalition is formed. 
Table 5: Group extraction

\begin{tabular}{|c|c|c|c|}
\hline & (1) & (2) & (3) \\
\hline veto & $\begin{array}{c}1.378^{* *} \\
(2.06)\end{array}$ & $\begin{array}{l}-1.423 \\
(-1.09)\end{array}$ & $\begin{array}{l}-2.274 \\
(-1.50)\end{array}$ \\
\hline period & $\begin{array}{c}-0.196^{*} \\
(-1.75)\end{array}$ & $\begin{array}{c}-0.371^{* * *} \\
(-6.31)\end{array}$ & $\begin{array}{c}-0.375^{* * *} \\
(-9.32)\end{array}$ \\
\hline grand & $\begin{array}{c}-6.451^{* * *} \\
(-6.71)\end{array}$ & $\begin{array}{c}-6.271^{* * *} \\
(-7.03)\end{array}$ & $\begin{array}{c}-10.984^{* * *} \\
(-9.33)\end{array}$ \\
\hline veto_lag_grand & & $\begin{array}{l}-1.595 \\
(-1.45)\end{array}$ & $\begin{array}{l}-0.346 \\
(-0.25)\end{array}$ \\
\hline veto_period & & $\begin{array}{c}0.410^{* * *} \\
(3.05)\end{array}$ & $\begin{array}{c}0.314^{* *} \\
(2.01)\end{array}$ \\
\hline$(4,1)$ & & & $\begin{array}{c}-6.427^{* * *} \\
(-4.20)\end{array}$ \\
\hline$(3,2)$ & & & $\begin{array}{c}-4.130^{* *} \\
(-2.30)\end{array}$ \\
\hline$(3,1,1)$ & & & $\begin{array}{c}-5.703^{* * *} \\
(-10.11)\end{array}$ \\
\hline$(2,2,1)$ & & & $\begin{array}{c}-5.526^{* * *} \\
(-4.68)\end{array}$ \\
\hline$(2,1,1,1)$ & & & $\begin{array}{c}-2.408^{* * *} \\
(-2.70)\end{array}$ \\
\hline _cons & $\begin{array}{c}22.853^{* * *} \\
(25.37)\end{array}$ & $\begin{array}{c}24.177^{* * *} \\
(25.86)\end{array}$ & $\begin{array}{c}29.218^{* * *} \\
(21.38)\end{array}$ \\
\hline $\mathrm{N}$ & 270 & 269 & 269 \\
\hline r2_o & 0.394 & 0.420 & 0.479 \\
\hline sigma_u & 0.000 & 0.000 & 0.000 \\
\hline $\mathrm{p}$ & 0.000 & 0.000 & . \\
\hline
\end{tabular}

\subsection{Individual Behavior}

Thus far, we established that the possibility to form coalitions has a tempering effect on group extractions and that the grand coalition always leads to lower extractions compared to other coalition structures. As grand coalitions are more frequent under the dictator treatment, it is not a surprise that group extractions are also lower. In this section, we focus on the effect of coalition size on individual extraction levels. To what extent does the coalition size affect the level of extraction? Table 6 reports the determinants of individual extractions based on OLS regressions 5

\footnotetext{
${ }^{5}$ The low frequency of extreme individual extractions, i.e. $0(0.44 \%)$ or $10(2.37 \%)$.
} 
with clustered errors at the player set level. Recall that extractions are uniform in each coalition, i.e. all members of a group have equal extraction levels and payoffs.

Table 6 provides a clear picture about individual extractions. First we observe from regression 1 and 4 that the treatment variable (veto) and coalition structures have no effect on individual extractions. The key determinant is the size of the coalition (i.e. sub-group size identified by the variable coalition_size $\mathrm{p}$ indicating that there are p subjects in a group) which has a negative impact on extractions: larger coalitions extract less as shown by the absolute value of the regression coefficient. This observation agrees with the theoretical predictions summarized in table 2. In addition, over time, whatever the size of the coalition, individual extractions tend to diminish. This effect seems mainly to be due to the more frequent formation of the grand coalition over time in both treatments. We summarize our observations in Result 4.

Result 4. Individual extractions are lower in larger coalitions, whatever the coalition structure and the treatment.

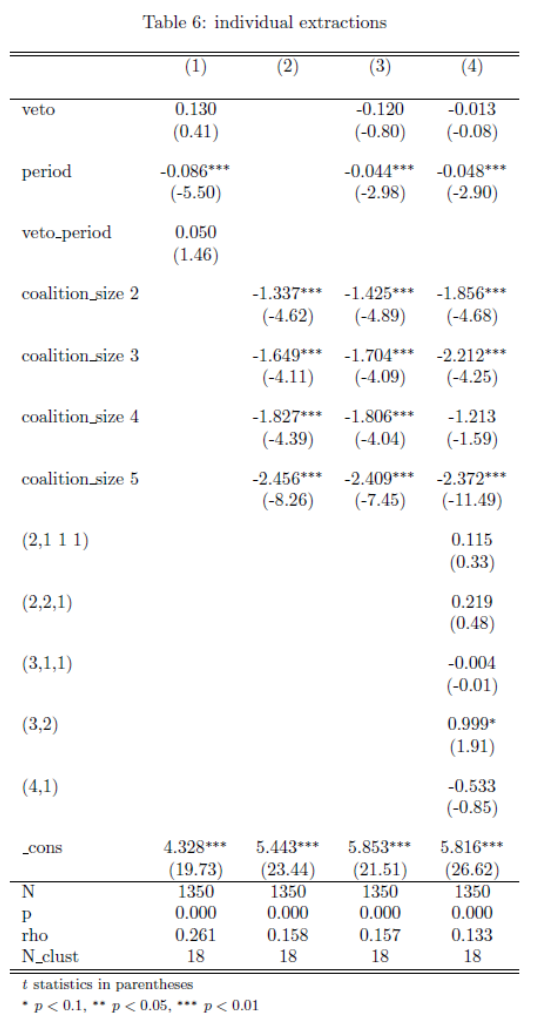

\section{Conclusion}


We have proposed a common-resource extraction game with endogenous coalition formation. The research questions are the following: 1) Are dictatorship and veto power different in terms of coalition formation in the commons? 2) If so, how do total group extraction rates differ? Overall, our experimental findings indicate that player sets characterized by veto power spread among all members are less likely to form the grand coalition, as compared with those where there is only one player who is assigned as decision-maker. Consequently, those in the veto treatment experience less efficient group extraction of the common-pool resource. From a decision-making perspective, such veto effect is detrimental because there is over-extraction of the resource compared to the optimum. Non-cooperation by just a single player will lead to failure to form a grand coalition. Nonetheless, we have found that subjects in the veto treatment benefit from the learning effect. If they have already agreed to form a grand coalition in the past, they are more likely to do so in the future. They seem to have been motivated to cooperate, after having experienced the potential benefits of larger coalitions (e.g. more efficient resource extraction and potentially higher group payoffs).

Finding in this paper has pertinent policy implications. This provides behavioral evidence on the unsustainability of a global coalition comprising of all players. When it comes to climate change negotiations and international environmental agreements, a grand coalition might be difficult if not impossible to achieve as long as all countries have veto power. If the incentive to deviate and not cooperate is high, then a larger coalition size is less likely. One possible solution is forming sub-groups with a sufficiently large set of countries (e.g. the EU having a joint climate target) and where group benefits are perceived to be high. Finally, we recommend extensions for future work. Potential research may include varying the veto power of players within one group, e.g. three players have veto power while the rest do not. Another possibility is varying the payoffs at stake. In that way, we can investigate whether increasing individual benefits from resource extraction will further hinder grand coalition formation.

\section{References}

Ahn, T.K., Isaac, M., Salmon, T.C., 2008. Endogenous group formation. Journal of Public Economic Theory 10, 171-194.

Ahn, T. K., Isaac, R. M., and Salmon, T. C. (2009), " Coming and going : Experiments on endogenous group sizes for excludable public goods is ", Journal of Public Economics, Elsevier B.V., Vol. 93, $\mathrm{n}^{\circ} 1-2$, p. 336-351. 
Barrett, S., 1994. Self enforcing international agreements. Oxford Economic Papers 46, 878-894.

Bloch, F., 1995. Endogenous Structures of Association in Oligopolies. Rand Journal of Economics, The Rand Corporation 26 (3), 537-556.

Bloch, F., 1996. Sequential formation of agreements with externalities and fixed payoff division. Games and Economic Behavior 14, 90-123.

Brekke, K. A., Hauge, K. E., Lind, J. T., and Nyborg, K. (2011), " Playing with the good guys. A public good game with endogenous group formation ", Journal of Public Economics, Elsevier B.V., Vol. 95, n 9-10, p. 1111-1118.

Carraro, C., Siniscalco, D., 1993. Strategies for the international protection of the environment. Journal of Public Economics 52, 309-328.

Chávez, C. A., Murphy, J. J. \& Stranlund, J. K., 2018. Managing and defending the commons: Experimental evidence from TURFs in Chile. Journal of Environmental Economics and Management, Volume 91, 229-246.

Chávez, C. A., Murphy, J. J., Quezada, F. J., and Stranlund, J. K. (2021), The Endogenous Formation of Common Pool Resource Coalitions. Working paper, 2021-01.

D'Aspremont, C., Gabszewicz, JeanJ., Jacquemin, A., Weymark, J.W., 1983. On the stability of collusive price leadership. Canadian Journal of Economics 17-25.

Finus, M., and McGinty, M. (2019). The anti-paradox of cooperation: Diversity may pay!, Journal of Economic Behavior and Organization, Elsevier B.V., Vol. 157, p. 541-559.

Funaki, Y. and Yamato T., 1999. The Core of an Economy with Common Pool Resource: A Partition Function Form Approach. International Journal Game Theory, Vol.28, 157-17.

Funaki, Y. and Yamato T., 2014. Stable coalition structures under restricted coalitional changes. International Game Theory Review. 16(3).

Hardin, G. (1968). The tragedy of the commons. Science, Vol. 162, n 3859, p. 1243-1248.

Hart, S., Kurz, M., 1983. Endogenous formation of coalitions. Econometrica 51, 1047-1064.

Hoel, M., Schneider, K., 1997. Incentives to participate in an international environmental agreement. Environmental and Resource Economics 9, 153-170.

Ehrhart, K.-M. , Keser, C. 1999. Mobility and Cooperation: On the Run. Cirano working papers.

Nordhaus, B. W. (2015). Climate Clubs : Overcoming free-riding in international climate policy, American Economic Review, Vol. 105, n 4, p. 1339-1370.

Pintassilgo, P. (2003). A coalition approach to the management of high seas fisheries in the presence of externalities, Natural Resource Modeling, Vol. 16, n 2, p. 175-197.

Pintassilgo, P., Finus, M., Lindroos, M., and Munro, G. (2010). Stability and success of regional fisheries management organizations, Environmental and Resource Economics, Vol. 46, n 3, p. 377-402.

Ray, D., Vohra, R., 1999. A theory of endogenous agreement structure. Games and Economic Behavior 26, 286-336.

Ray, D., Vohra, R., 2001. Coalitional power of public goods. Journal of Political Economy 109, 6.

Thoron, S., Sol, E., and Willinger, M. (2009), " Do binding agreements solve the social dilemma? ", Journal of Public Economics, Elsevier B.V., Vol. 93, n 11-12, p. 1271-1282. 


\title{
Appendix
}

\section{APPENDIX 1: Instructions}

\author{
*************************** \\ Extended instructions: Dictator [Veto] treatment \\ Part 2 \\ You will now participate in the second part of the experiment. This part contains 15 periods. The \\ composition of the groups of 5 people remains identical to that of the first part of the experiment. It will \\ remain so until the end of the experiment. Your gains for a period will depend on both your decisions and \\ the decisions made by the other 4 members of your set. The following instructions will help you \\ understand how your earnings are determined.
}

\section{Decision}

During a period, two types of decisions will be taken successively (step 1 and step 2) within each set of 5 players:

Step 1: You will have to form groups of players within your set of 5 players. Each member of your set can belong to only one group. The sizes of these groups must be between 1 and 5 players. For example there can be 5 groups of 1 player, or a single group of 5 players. But there can also be 1 group of 4 players and a group of 1 player, 2 groups of 2 players and a group of 1 player and 1 group of 3 players and 1 group of 2 players. The rules for forming groups will be explained below.

Step 2: Each member of your group will be asked to allocate his endowment of 10 tokens between his individual account and the collective account. Unlike the first part of the experiment, members of a group will not be able to freely choose their investment in the collective account. All members of the same group will be required to allocate the same number of tokens to the collective account. The decision rules are explained below.

We will now detail the two mentioned decision steps:

\section{1st step: group formation.}


The groups are formed as follows: at the start of step 1, one of the 5 members of your set will be selected randomly to make a proposal. His proposal will consist of announcing a group size between 1 and 5. If, for example, he wishes to bring together all the members of the set in a single group, he will choose the number 5 . On the contrary, if he prefers to constitute a group on his own he will choose the number 1 . If he chooses to form a singleton, his decision will be immediately applied, and he will remain alone for the rest of the current period. If he chooses to form a larger group, the other members selected for his group will be chosen at random from among the 4 other members of the subset (except if he chose a group of 5 in which case they will all be selected). A member selected for being part of a group cannot refuse: he will therefore automatically be part of the group if selected.

Example: The first player designated to form a group announces the number 3. The player who makes the proposal is automatically part of his group. The other two members are randomly selected among the 4 remaining persons in the set. Each member of the set has the same chances of being selected to be part of the group formed by this player, namely 2 chances out of 4 . The two people selected cannot refuse to become a member of the group.

[... If during a period you are offered to join a group, you will have to decide whether to accept or reject this offer. If you accept and all the members proposed for your group also accept, the group will be definitively formed. If you refuse, or if one of the proposed members for your group refuses, the group will not be formed. One of the players who refused will then be designated to make a new proposal...]

If the group formed includes all the 5 members of the set, step 1 is complete. If the group formed has 4 members, the member who remains alone has no other choice than to form a group on his own. If the group formed includes the 5 members of the set everyone is part of a group. If the group formed has 3 members or less, a new draw is made among the players who are not already part of the group constituted, in order to designate a player responsible for forming a second group. As for the first group, the designated player will simply choose the size of the group he wants to constitute, considering the number of players remaining. If, for example, the group already formed includes exactly 2 players, the size of the second group may include either a single player, two players, or three players. When the size of the second group is announced, its members will be chosen randomly among the remaining players who are not part of the group already formed. Members selected to be part of the second group cannot refuse to be part of it. If two groups are formed, and more than one unassigned player remains in a formed group, the process described above continues. A new player is drawn to form the third group and so on. This process continues until all players are part of a group. When all players are finally assigned to a group, the group structure formed in your set will be displayed on your screen. The different possibilities are as follows: 


\begin{tabular}{|c|l|}
\hline Coalition structure & \\
\hline$(5)$ & 1 group of five players \\
\hline$(4,1)$ & 1 group of 4 players and 1 group of 1 player \\
\hline$(3,2)$ & 1 group of 3 players and 1 group of 2 player \\
\hline$(3,1,1)$ & 1 group of 3 players and 2 groups of 1 player \\
\hline$(2,2,1)$ & 2 group of 2 players and 1 group of 1 player \\
\hline$(2,1,1,1)$ & 1 group of 2 players and 3 groups of 1 player \\
\hline$(1,1,1,1,1)$ & 5 groups of 1 player \\
\hline
\end{tabular}

Once all groups are formed and the list has been announced, the second step will begin.

\section{2nd step: the investment.}

The players who formed the groups in step 1 (referred to as "founding member" hereafter) will have to decide how to allocate their initial endowment (10 tokens) between their individual account and the collective account. All members belonging to the same group must adopt the same allocation of their endowment as the founding member. For example, if the founding member decides to invest 3 tokens in the collective account, all members of his group must also invest 3 tokens in the collective account.

As for the first part of the experiment, the collective account is common to the 5 members of the set, regardless of their group. For example if two groups are formed (a group of 3 and a group of 2), the collective account will benefit each of the 5 people, regardless of their group belonging.

Example 1: You are the founding member of a group of 3 and you decide to invest 4 tokens in the collective account. The other 2 members of your group will also be required to invest 4 tokens in the collective account which is common to all the players of your set (the 5 players in your set).

Example 2: You have been designated to be part of a group of 4 players. You do not have the possibility of choosing yourself the amount you want to invest in the collective account. You will need to invest the same amount as the founding member of your group.

\section{Choice of group size and allocation of your endowment}

To each group structure $\{(5),(4,1),(3,1,1),(2,1,1,1),(1,1,1,1,1),(3,2),(2,2,1)\}$ corresponds a different payoff table. The payoff depends on two components: your investment in the collective account and the total investment of your set in the collective account. You can view the payoff table of a given 
structure by clicking on the corresponding button. For example, you can visualize the payoff table of the structure $(4,1)$ by clicking on the button $(4,1)$.

For this stage of the game, if you are a founding member, your role will be to choose the level of investment that you, and each other member of your group, have to invest in the collective account that is common to all the members of your set.

\section{Summary of the procedure}

At the start of each period you will be endowed with 10 tokens. You will then eventually be selected to be the founding member of a group. To form a group you must choose its size among the possible sizes. If you are the first founding member, you can choose any group size between 1 and 5 . If a group is already constituted and that you are randomly selected to constitute a second group, you can choose only among the remaining possible sizes. A player selected to be part of a group cannot refuse.

Once all players of your set are assigned to a group, step 2 will begin. Each founding member of a group will then choose the level of investment in the collective account for his group. Each member of a group will invest the same amount in the collective account than that decided by the founding member.

Your payoff for a period will depend on the number of groups in your set, the size of each group, the investment in the collective account which is decided by each founding member of each group and the total investment of your set.

When all the founding members have made their investment decision, the computer will display the summary of the period, namely: the group structure that is formed, the size of your group, your investment in the collective account, the total investment of your group in the collective account, the total investment of your set in the collective account your gain for the period. When all participants have clicked on the button "validate" from the summary screen, the following period will begin. You can at any time view the history of previous periods by clicking on the "History" button. The "History" table gives you, for previous periods: the realized group structure, the size of your group, the number of tokens you invested in the collective account, the total number of tokens invested in the collective account by your group, the number total tokens invested in the collective account by your set, your corresponding gain for the period and your cumulative gain since the first period of the game. When the 15 th period is over, the computer will display your gain for the experiment in ecus, and its conversation in euros. The conversion rate is, as in the part $1,1 \mathrm{ecu}=0.02$ euros. 


\section{APPENDIX 2: Screenshots}

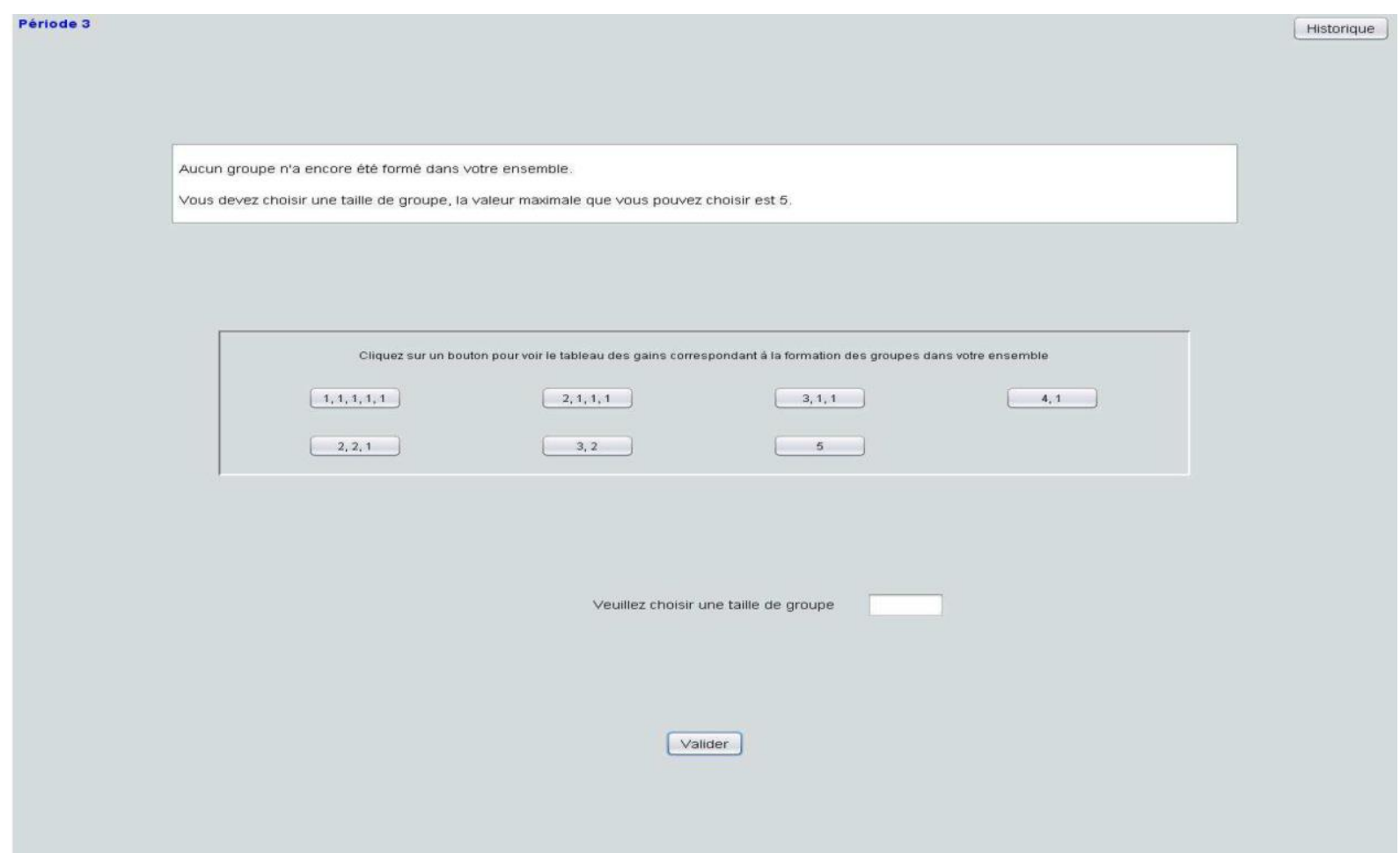

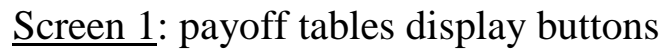

Screen 1 was available before the selection of the proposer. By clicking on one of the buttons participants could consult the corresponding payoff table (see an illustration below on screen 2). 


\begin{tabular}{|c|c|c|c|c|c|c|c|c|c|c|c|}
\hline & & & se & Invest 1 & ent & dans $1 \mathrm{e}$ & compte & collect & $(\mathrm{x})$ & & \\
\hline & 0 & 1 & 2 & 3 & 4 & 5 & 6 & 7 & 8 & 9 & 10 \\
\hline 0 & 10 & 40 & 70 & 100 & 130 & 160 & 190 & 220 & 250 & 280 & 310 \\
\hline 1 & 10 & 39 & 68 & 97 & 126 & 155 & 184 & 213 & 242 & 271 & 300 \\
\hline 2 & 10 & 38 & 66 & 94 & 122 & 150 & 178 & 206 & 234 & 262 & 290 \\
\hline 3 & 10 & 37 & 64 & 91 & 118 & 145 & 172 & 199 & 226 & 253 & 280 \\
\hline 4 & 10 & 36 & 62 & 88 & 114 & 140 & 166 & 192 & 218 & 244 & 270 \\
\hline 5 & 10 & 35 & 60 & 85 & 110 & 135 & 160 & 185 & 210 & 235 & 260 \\
\hline 6 & 10 & 34 & 58 & 82 & 106 & 130 & 154 & 178 & 202 & 226 & 250 \\
\hline 7 & 10 & 33 & 56 & 79 & 102 & 125 & 148 & 171 & 194 & 217 & 240 \\
\hline 8 & 10 & 32 & 54 & 76 & 98 & 120 & 142 & 164 & 186 & 208 & 230 \\
\hline 9 & 10 & 31 & 52 & 73 & 94 & 115 & 136 & 157 & 178 & 199 & 220 \\
\hline 10 & 10 & 30 & 50 & 70 & 90 & 110 & 130 & 150 & 170 & 190 & 210 \\
\hline 11 & 10 & 29 & 48 & 67 & 86 & 105 & 124 & 143 & 162 & 181 & 200 \\
\hline 12 & 10 & 28 & 46 & 64 & 82 & 100 & 118 & 136 & 154 & 172 & 190 \\
\hline 13 & 10 & 27 & 44 & 61 & 78 & 95 & 112 & 129 & 146 & 163 & 180 \\
\hline 14 & 10 & 26 & 42 & 58 & 74 & 90 & 106 & 122 & 138 & 154 & 170 \\
\hline 15 & 10 & 25 & 40 & 55 & 70 & 85 & 100 & 115 & 130 & 145 & 160 \\
\hline 16 & 10 & 24 & 38 & 52 & 66 & 80 & 94 & 108 & 122 & 136 & 150 \\
\hline 17 & 10 & 23 & 36 & 49 & 62 & 75 & 88 & 101 & 114 & 127 & 140 \\
\hline 18 & 10 & 22 & 34 & 46 & 58 & 70 & 82 & 94 & 106 & 118 & 130 \\
\hline 19 & 10 & 21 & 32 & 43 & 54 & 65 & 76 & 87 & 98 & 109 & 120 \\
\hline 20 & 10 & 20 & 30 & 40 & 50 & 60 & 70 & 80 & 90 & 100 & 110 \\
\hline 21 & 10 & 19 & 28 & 37 & 46 & 55 & 64 & 73 & 82 & 91 & 100 \\
\hline 22 & 10 & 18 & 26 & 34 & 42 & 50 & 58 & 66 & 74 & 82 & 90 \\
\hline 23 & 10 & 17 & 24 & 31 & 38 & 45 & 52 & 59 & 66 & 73 & 80 \\
\hline 24 & 10 & 16 & 22 & 28 & 34 & 40 & 46 & 52 & 58 & 64 & 70 \\
\hline 25 & 10 & 15 & 20 & 25 & 30 & 35 & 40 & 45 & 50 & 55 & 60 \\
\hline 26 & 10 & 14 & 18 & 22 & 26 & 30 & 34 & 38 & 42 & 46 & 50 \\
\hline 27 & 10 & 13 & 16 & 19 & 22 & 25 & 28 & 31 & 34 & 37 & 40 \\
\hline 28 & 10 & 12 & 14 & 16 & 18 & 20 & 22 & 24 & 26 & 28 & 30 \\
\hline 29 & 10 & 11 & 12 & 13 & 14 & 15 & 16 & 17 & 18 & 19 & 20 \\
\hline 30 & 10 & 10 & 10 & 10 & 10 & 10 & 10 & 10 & 10 & 10 & 10 \\
\hline 31 & 10 & 9 & 8 & 7 & 6 & 5 & 4 & 3 & 2 & 1 & 0 \\
\hline 32 & 10 & 8 & 6 & 4 & 2 & 0 & -2 & -4 & -6 & -8 & -10 \\
\hline 33 & 10 & 7 & 4 & 1 & -2 & -5 & -8 & -11 & -14 & -17 & -20 \\
\hline 34 & 10 & 6 & 2 & -2 & -6 & -10 & -14 & -18 & -22 & -26 & -30 \\
\hline 35 & 10 & 5 & 0 & -5 & -10 & -15 & -20 & -25 & -30 & -35 & -40 \\
\hline 36 & 10 & 4 & -2 & -8 & -14 & -20 & -26 & -32 & -38 & -44 & -50 \\
\hline 37 & 10 & 3 & -4 & -11 & -18 & -25 & -32 & -39 & -46 & -53 & -60 \\
\hline 38 & 10 & 2 & -6 & -14 & -22 & -30 & -38 & -46 & -54 & -62 & -70 \\
\hline 39 & 10 & 1 & -8 & -17 & -26 & -35 & -44 & -53 & -62 & -71 & -80 \\
\hline 40 & 10 & 0 & -10 & -20 & -30 & -40 & -50 & -60 & -70 & -80 & -90 \\
\hline 41 & 10 & -1 & -12 & -23 & -34 & -45 & -56 & -67 & -78 & -89 & -100 \\
\hline 42 & 10 & -2 & -14 & -26 & -38 & -50 & -62 & -74 & -86 & -98 & -110 \\
\hline 43 & 10 & -3 & -16 & -29 & -42 & -55 & -68 & -81 & -94 & -107 & -120 \\
\hline 44 & 10 & -4 & -18 & -32 & -46 & -60 & -74 & -88 & -102 & -116 & -130 \\
\hline 45 & 10 & -5 & -20 & -35 & -50 & -65 & -80 & -95 & -110 & -125 & -140 \\
\hline 46 & 10 & -6 & -22 & -38 & -54 & -70 & -86 & -102 & -118 & -134 & -150 \\
\hline 47 & 10 & -7 & -24 & -41 & -58 & -75 & -92 & -109 & -126 & -143 & -160 \\
\hline 48 & 10 & -8 & -26 & -44 & -62 & -80 & -98 & -116 & -134 & -152 & -170 \\
\hline 49 & 10 & -9 & -28 & -47 & -66 & -85 & -104 & -123 & -142 & -161 & -180 \\
\hline 50 & 10 & -10 & -30 & -50 & -70 & \begin{tabular}{|c|}
-90 \\
\end{tabular} & -110 & -130 & -150 & -170 & -190 \\
\hline
\end{tabular}

Screen 2: payoff table corresponding to the coalition structure $(3,2)$.

Payoffs were presented as a function of the player's own investment (columns) from 0 to 10 tokens, and the total investment of his player set (lines) from 0 to 50 tokens. Activated cells show the possible combinations of tokens investment taking into account that extraction levels are uniform within each group. 


\section{CEE-M Working Papers' - 2021}

WP 2021-01

WP 2021-02

WP 2021-03

WP 2021-04

WP 2021-05

WP 2021-06

WP 2021-07

WP 2021-08

WP 2021-09
Philippe Mahenc \& Alexandre Volle «Price Signaling and Quality Monitoring in Markets for Credence Goods»

Mamadou Gueye, Nicolas Quérou, \& Raphael Soubeyran "Inequality Aversion and the Distribution of Rewards in Organizations»

Lesly Cassin, Paolo Melindi-Ghidi \& Fabien Prieur « Voting for environmental policy with green consumers: the impact of income inequality »

Marion Davin \& Emmanuelle Lavaine

« The Role Of Health At Birth And Parental Investment In Early Child Development. Evidence From The French ELFE Cohort »

Ko Serge William Yao, Emmanuelle Lavaine \& Marc Willinger " Does the approval mechanism induce the effcient extraction in Common Pool Resource games?»

Raphaël Soubeyran

«Pro-social Motivations, Externalities and Incentives »

Murielle Djiguemde, Dimitri Dubois, Alexandre Sauquet $\&$ Mabel Tidball "Continuous versus Discrete Time in Dynamic Common Pool Resource Game Experiments »

Marion Davin, Mouez Fodha \& Thomas Seegmuller «Environment, public debt and epidemics »

Marc Willinger, Oussama Rhouma \& Klarizze Anne Puzon

"Veto power and coalition formation in the commons: an experiment »

\footnotetext{
${ }^{1}$ CEE-M Working Papers / Contact : laurent.garnier@inra.fr

- RePEc https://ideas.repec.org/s/hal/wpceem.html

- HAL https://halshs.archives-ouvertes.fr/CEE-M-WP/
} 